\title{
Characterization and thermal behaviour of lanthanum tartrate crystals grown from silica gels
}

\author{
P N KOTRU, N K GUPTA, K K RAINA and M L KOUL $\dagger$ \\ Department of Physics, †Department of Chemistry, University of Jammu, Jammu 180001 , \\ India \\ MS received 15 February 1986; revised 7 May 1986

\begin{abstract}
Results obtained on characterization of lanthanum tartrate crystals, grown by the gel method, using chemical analysis, $x$-ray and electron diffraction, infra-red and mass spectroscopy are reported. The thermal behaviour is studied using DTA, TGA and DTG. The decomposition pattern is reported to be typical of a hydrated metal tartrate. Kinetic parameters like order of reaction, frequency factor and activation energy are evaluated. Contracting cylinder kinetic model is found to be the best fit for the decomposition processes involved. Magnetic susceptibility measurements indicate the material to be
\end{abstract} \\ diamagnetic.
}

Keywords. Lanthanum tartrate crystal; thermal behaviour; silica gels.

\section{Introduction}

Rare-earth materials have attracted considerable attention on account of their luminescent and magnetic properties (Eyring 1964). The present efforts have been initiated to obtain rare-earth tartrates for various investigations. However, it is necessary to establish the exact chemical composition and other characteristics of the material. In the present work the crystals of $\mathrm{La}_{2}\left(\mathrm{C}_{4} \mathrm{H}_{4} \mathrm{O}_{6}\right)_{3} \cdot 7 \mathrm{H}_{2} \mathrm{O}$ were grown by using the controlled diffusion system of silica gels (Kotru et al 1985). Crystals of varied morphologies grown in the gel media are shown in figure 1. A literature survey showed that no studies have been carried out on the growth or the $\mathrm{x}$-ray diffraction data on lanthanum tartrate crystals. The present characterization of lanthanum tartrate crystals is therefore studied and the results obtained from chemical analysis, infra-red and mass spectroscopy, $x$-ray and electron diffraction and thermal analysis are discussed.

\section{Experimental details}

To determine the contents of lanthanum (metal), carbon and hydrogen, the material was subjected to conventional physical and chemical methods. Carbon-hydrogen analysis was performed and x-ray diffraction pattern recorded on the powdered samples using X-ray powder diffractometer (Phillips model PW1350) with nickelfiltered $\mathrm{CuK} \alpha$ radiations $(30 \mathrm{kV}, 15 \mathrm{~mA})$. Electron diffraction was obtained by using transmission electron microscope (AEI TEM-802, UK). Mass spectrum was recorded using JMS-300 at $70 \mathrm{eV}$. The IR spectrum (range: 300 to $4000 \mathrm{~cm}^{-1}$ ) was recorded by employing Spektromom 2000, using $\mathrm{KBr}$ pellet technique. Thermal analysis, involving DTA, TGA and DTG techniques was carried out using a MOM derivatograph (Paulik-Paulik-Eredey Hungary) at the heating rate of $10^{\circ} \mathrm{C} / \mathrm{min}$. The 


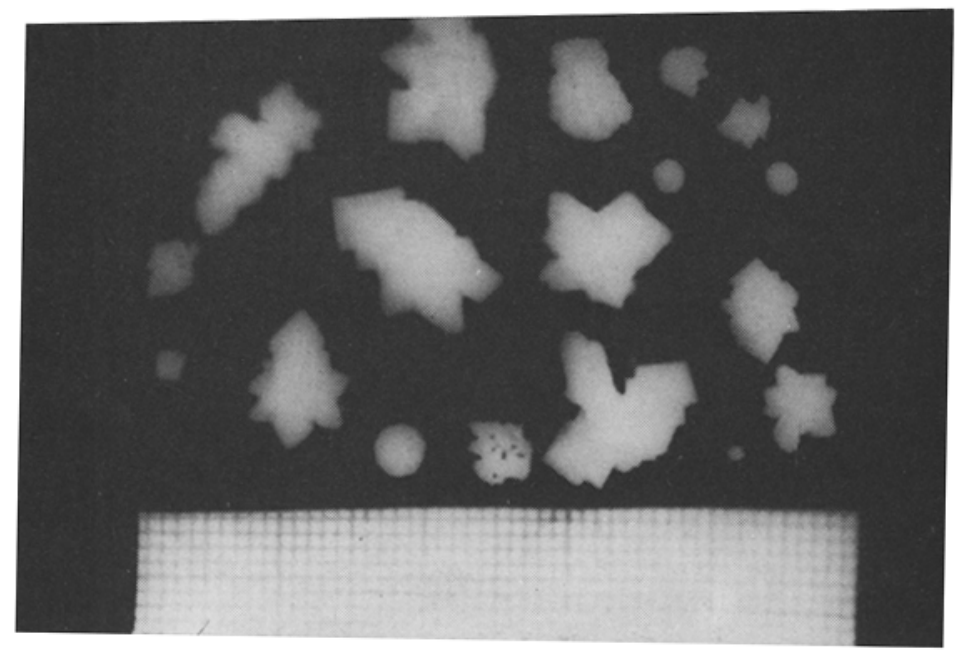

Figure 1. Gel grown crystals of $\mathrm{La}_{2}\left(\mathrm{C}_{4} \mathrm{H}_{4} \mathrm{O}_{4}\right)_{3} \cdot 7 \mathrm{H}_{2} \mathrm{O}$ of different morphologies.

weight of the sample used was $200 \mathrm{mg}$. To identify the final product in TG analysis, $x$-ray powder pattern was recorded after heating the original compound to $850^{\circ} \mathrm{C}$ in an electronically controlled muffle furnace working within an accuracy of $\pm 10^{\circ} \mathrm{C}$. Kinetic parameters of solid state reactions from the thermal analysis such as activation energy, order of reaction and frequency factor were determined by using different thermo-analytical kinetic equations and Gouy's balance was used for magnetic susceptibility measurements.

\section{Results and discussion}

\subsection{Chemical analysis}

To establish the chemical composition of crystals grown, the metal and carbonhydrogen analysis was made use of. The chemical composition of the material was $\mathrm{La}_{2}\left(\mathrm{C}_{4} \mathrm{H}_{4} \mathrm{O}_{6}\right)_{3} \cdot 7 \mathrm{H}_{2} \mathrm{O}$. These results are further supported by TGA in which after the mass loss of $63 \% \mathrm{La}_{2} \mathrm{O}_{3}$ is formed. The TGA results also agree with those obtained from chemical analysis.

\section{$3.2 X$-ray analysis}

The x-ray diffractogram recorded (figure 2) indicates the crystallinity of the sample. Table 1 shows the $\mathrm{x}$-ray diffraction data for $\mathrm{La}_{2}\left(\mathrm{C}_{4} \mathrm{H}_{4} \mathrm{O}_{6}\right)_{3} \cdot 7 \mathrm{H}_{2} \mathrm{O}$.

\subsection{TEM results}

TEM was used to establish the crystallinity of the sample. It is seen that there is a decomposition resulting in the change of the diffraction pattern. Figures $3(a)$ and $3(b)$ 


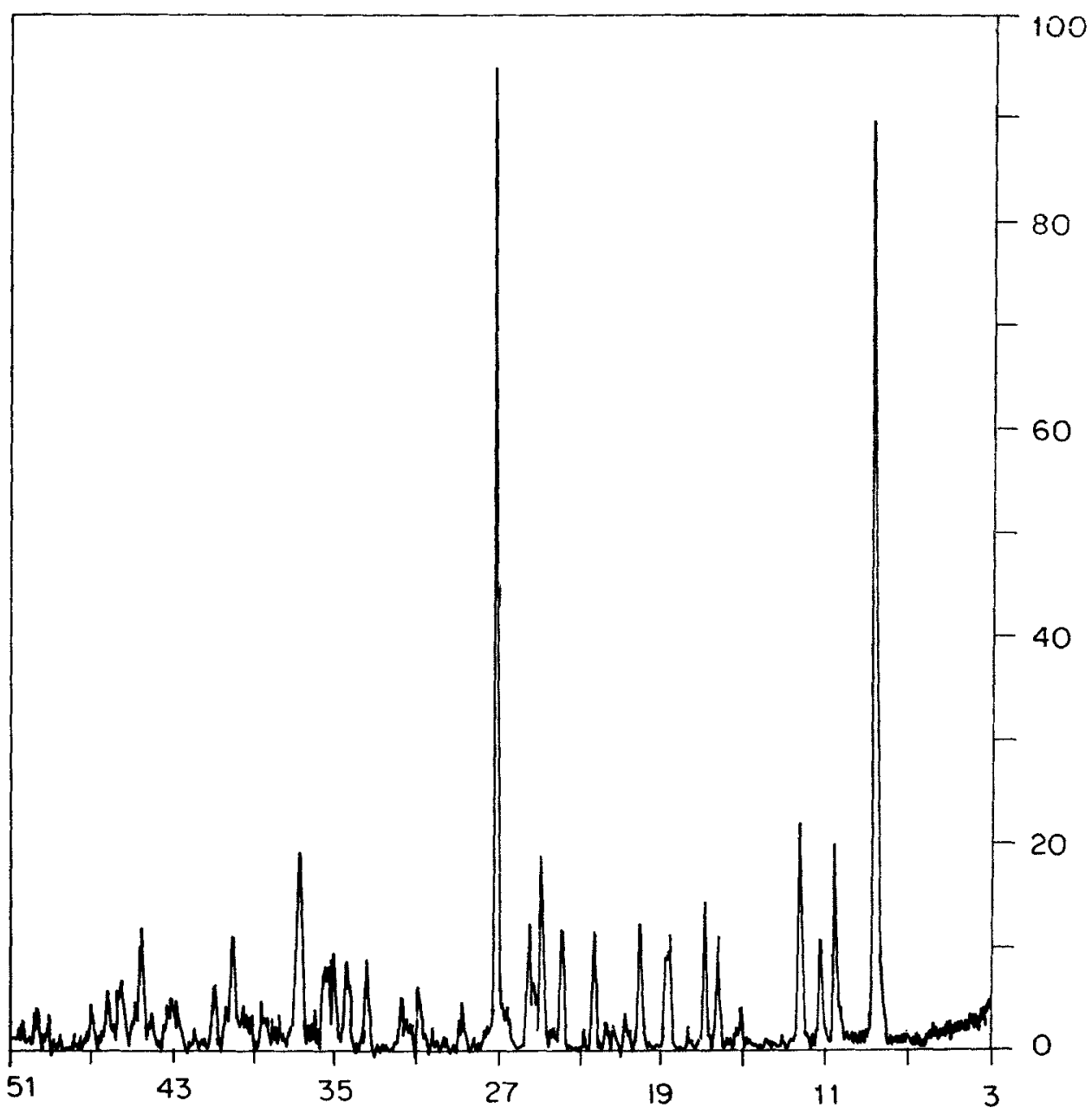

Figure 2. X-ray diffraction trace.

Table 1. X-ray powder data.

\begin{tabular}{rc}
\hline$d$ values & Intensity values \\
\hline 10.0480 & $89 \cdot 5$ \\
8.2678 & $20 \cdot 0$ \\
7.0810 & 22.0 \\
$5 \cdot 3402$ & $9 \cdot 0$ \\
5.1257 & $12 \cdot 0$ \\
4.6707 & 9.0 \\
4.3532 & 10.0 \\
3.9342 & 11.5 \\
3.5339 & 19.0 \\
3.2433 & 95.0 \\
2.4332 & 19.0 \\
2.2378 & 11.0 \\
2.0273 & 12.0 \\
\hline
\end{tabular}



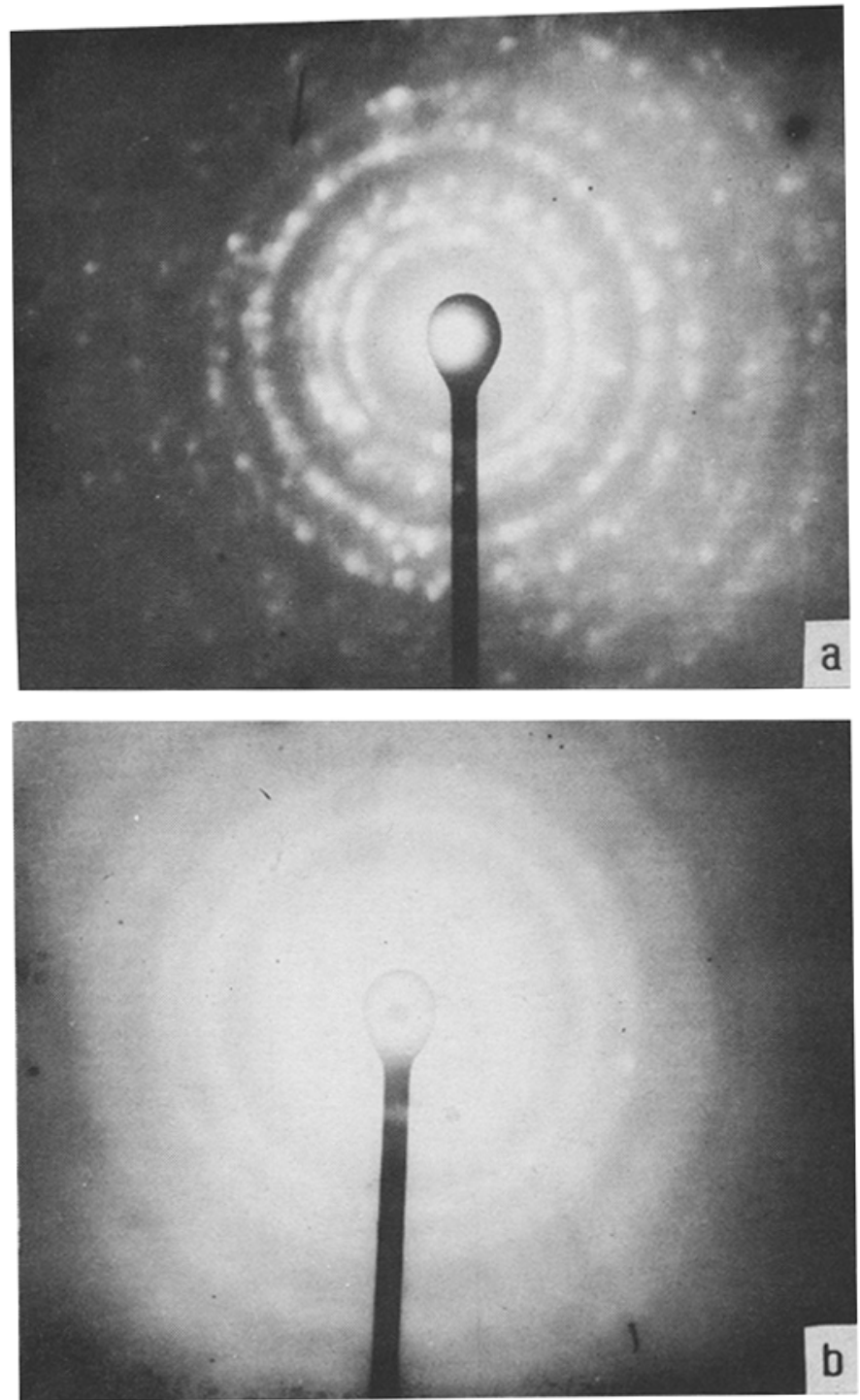

Figure 3. (a) Electron diffraction pattern recorded immediately on koading and $|\boldsymbol{b}|$ electron diffraction pattern recorded after some time of loading.

are electron diffraction patterns of the material recorded immediately or after some time of loading. The pattern shown in figure 3(a) indicates the crystallinity of the material. A comparison between figures $3(a)$ and $3(b)$ shows that the diffraction pattern changed from polycrystalline to nearly amorphous pattern (Kotru and Gupta 1983). This could be due to the presence of water in the original material.

\subsection{Mass spectroscopy}

Mass spectrum of the crystal sample was recorded using $70 \mathrm{eV}$ electron bombardment for ionization. Figure 4 shows the mass spectrum of $\mathrm{La}_{2}\left(\mathrm{C}_{4} \mathrm{H}_{4} \mathrm{O}_{6}\right)_{3} \cdot 7 \mathrm{H}_{2} \mathrm{O}$. 


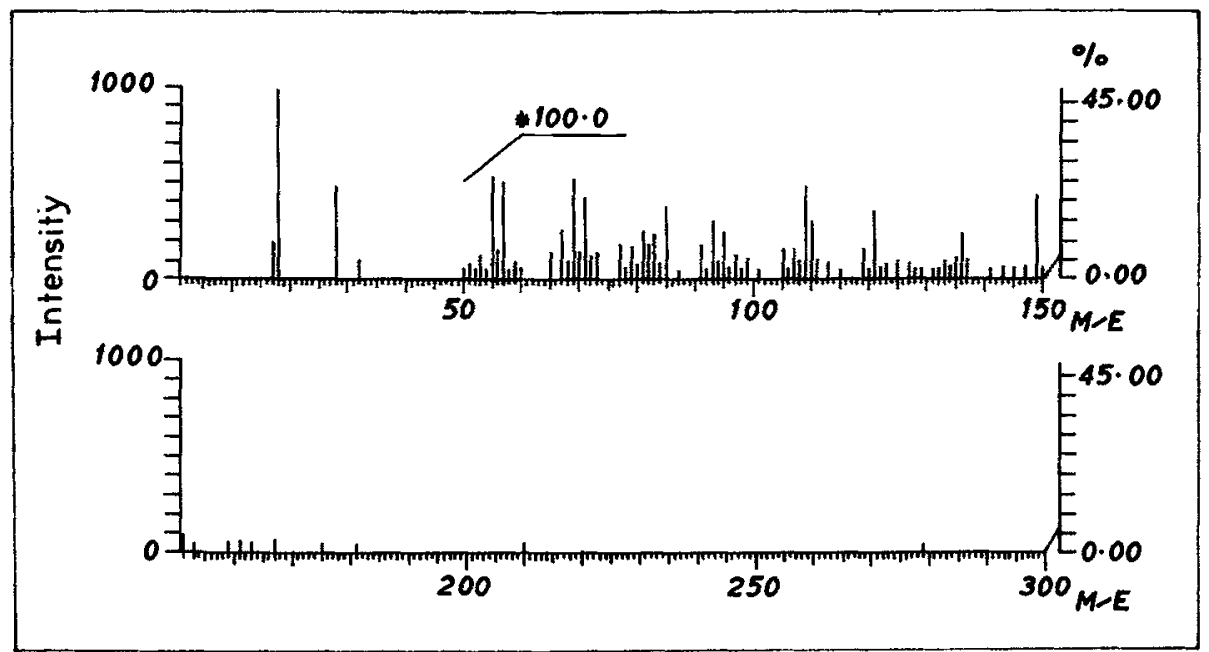

Figure 4. Mass spectrum of $\mathrm{La}_{2}\left(\mathrm{C}_{4} \mathrm{H}_{4} \mathrm{O}_{6}\right)_{3} \cdot 7 \mathrm{H}_{2} \mathrm{O}$ crystals.

Table 2. Mass spectrum data corresponding to significant peaks of $\mathrm{La}_{2}\left(\mathrm{C}_{4} \mathrm{H}_{4} \mathrm{O}_{6}\right)_{3} \cdot 7 \mathrm{H}_{2} \mathrm{O}$.

\begin{tabular}{rrrc}
\hline M/E & Raw int. & $\begin{array}{c}\text { Relative } \\
\text { intensity }\end{array}$ & Sigma (\%) \\
\hline 16.0 & $11 \cdot 1$ & 13.9 & 0.68 \\
17.0 & 169.9 & 212.0 & 10.40 \\
18.0 & 801.2 & 1000.0 & 49.04 \\
28.0 & 388.8 & 485.2 & 23.79 \\
32.0 & 87.0 & 108.5 & 5.32 \\
43.0 & 10.3 & 12.9 & 0.63 \\
44.0 & 16.9 & 21.0 & 1.03 \\
149.0 & 3.4 & 4.3 & 0.21 \\
\hline
\end{tabular}

The mass fragmentography corresponding to prominent peaks is indicated in table 2 . The base peak of $\mathrm{M} / \mathrm{E} 18$ suggests the possible presence of water of crystallization. The M/E peak at 149 may be due to the tartrate constituent of the parent material.

The mass spectrum suggests the decomposition of the material and further supports the presence of water, carbon and oxygen as constituents of the crystal sample which is expected on fragmentation of the tartrate and water of crystallization in the parent material. To find out if there was any volatility, repeated experiments were performed to capture the molecular ion along with the metal, but they failed to yield the desired results indicating that the molecule got decomposed before it was captured.

\subsection{IR spectrum results}

Figure 5 shows the infra-red spectra of $\mathrm{La}_{2}\left(\mathrm{C}_{4} \mathrm{H}_{4} \mathrm{O}_{6}\right)_{3} \cdot 7 \mathrm{H}_{2} \mathrm{O}$. The peak $3400 \mathrm{~cm}^{-1}$ is due to water and strongly stretching modes of $\mathrm{OH}$ group. The bands near 1265 


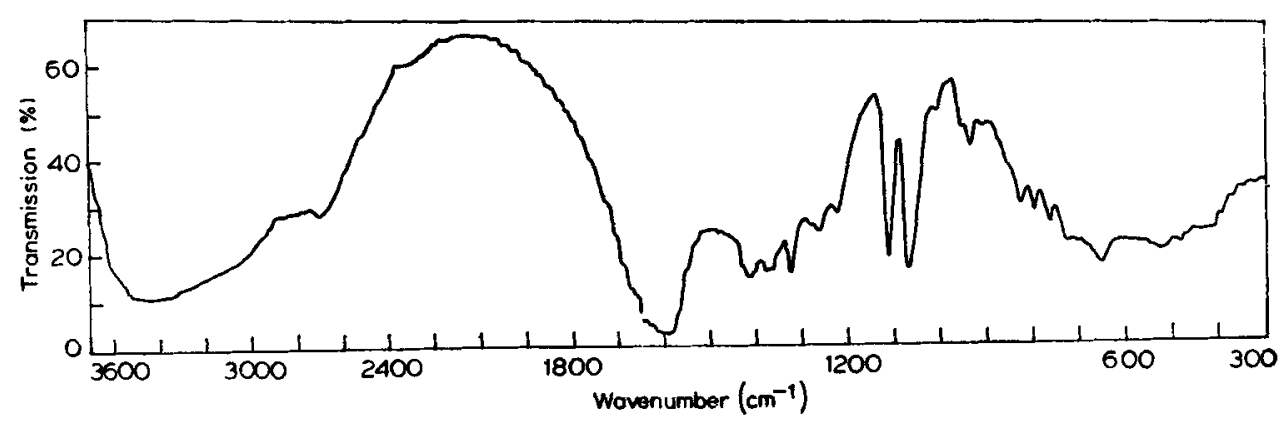

Figure 5. Infra-red spectrum of $\mathrm{La}_{2}\left(\mathrm{C}_{4} \mathrm{H}_{4} \mathrm{O}_{6}\right)_{3} \cdot 7 \mathrm{H}_{2} \mathrm{O}$ crystals.

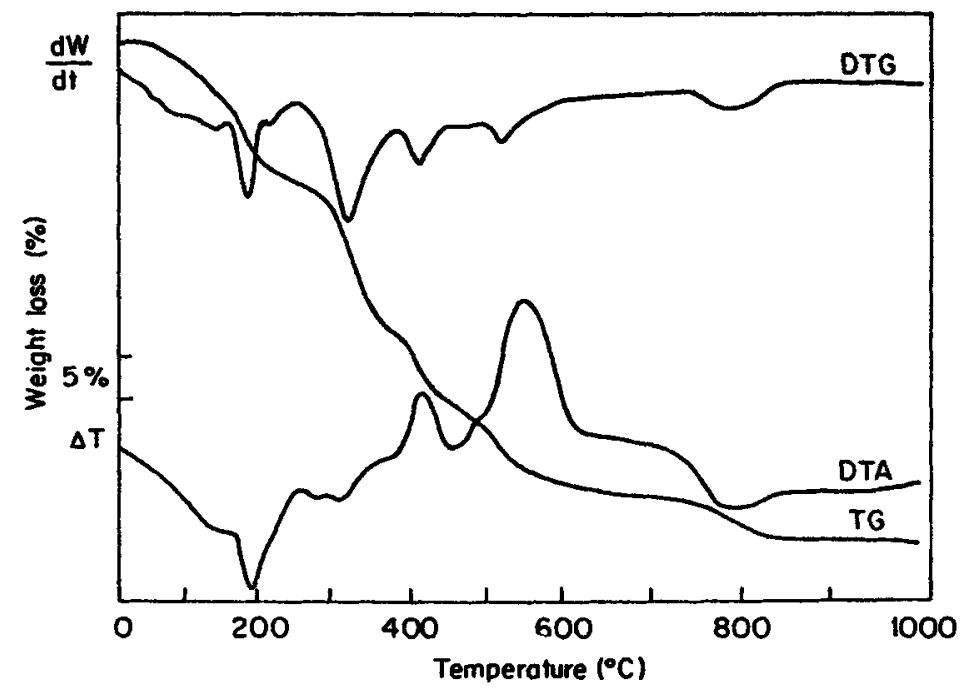

Figure 6. Thermogram showing TGA, DTA and DTG curves for $\mathrm{La}_{2}\left(\mathrm{C}_{4} \mathrm{H}_{4} \mathrm{O}_{6}\right)_{3} \cdot 7 \mathrm{H}_{2} \mathrm{O}$ crystals.

and $1370 \mathrm{~cm}^{-1}$ may be attributed to $\mathrm{OH}$ in plane bending. While the band at $1590 \mathrm{~cm}^{-1}$ is due to $\mathrm{C}=\mathrm{O}$ stretch, those at 1415 and $1325 \mathrm{~cm}^{-1}$ are due to $\mathrm{CO}$ sym $+\delta \mathrm{O}-\mathrm{C}=\mathrm{O}$ modes. The modes of $\delta \mathrm{C}-\mathrm{H}$ and $\pi \mathrm{C}-\mathrm{H}$ are indicated by bands at 1115 and $1070 \mathrm{~cm}^{-1}$. A significant band is observed at $650 \mathrm{~cm}^{-1}$ which is attributed to the presence of crystal water (Niekerk and Schoening 1951). Besides, there are some peaks below $500 \mathrm{~cm}^{-1}$ indicating metal oxygen bond.

\subsection{Thermal analysis}

Figure 6 shows the thermogram for TGA, DTA and DTG for $\mathrm{La}_{2}\left(\mathrm{C}_{4} \mathrm{H}_{4} \mathrm{O}_{6}\right)_{3} \cdot 7 \mathrm{H}_{2} \mathrm{O}$. It is seen from TGA that the material starts decomposing around $60^{\circ} \mathrm{C}$ and the process is completed after the mass loss attains saturation. Some of the decomposition steps in the TG show considerable overlapping but are very much distinct in 
Table 3. Results of decomposition process of $\mathrm{La}_{2}\left(\mathrm{C}_{4} \mathrm{H}_{4} \mathrm{O}_{6}\right)_{3} \cdot 7 \mathrm{H}_{2} \mathrm{O}$.

\begin{tabular}{lccc}
\hline $\begin{array}{l}\text { Temperature } \\
\text { range } \\
\left({ }^{\circ} \mathrm{C}\right)\end{array}$ & $\begin{array}{c}\text { Observed } \\
\text { mass loss } \\
(\%)\end{array}$ & $\begin{array}{c}\text { Calculated } \\
\text { mass loss } \\
(\%)\end{array}$ & $\begin{array}{c}\text { Loss of } \\
\text { molecules } \\
\text { in the step }\end{array}$ \\
\hline $60-200$ & $14 \cdot 51$ & 14.85 & $7 \mathrm{H}_{2} \mathrm{O}$ \\
$200-370$ & 35.00 & 36.08 & $6 \mathrm{H}_{2} \mathrm{O}+6 \mathrm{C}$ \\
$370-470$ & 45.00 & 45.99 & $3 \mathrm{CO}$ \\
$470-610$ & 55.50 & 56.36 & $2 \mathrm{CO}_{2}$ \\
$610-835$ & 62.00 & 61.55 & $\mathrm{CO}_{2}$ \\
\hline
\end{tabular}

the DTG curve. A combined study of TG and DTG indicates a decomposition pattern as given in table 3 .

The DTA curve also indicates peaks corresponding to the DTG peaks. The first two stages in DTA are endothermic and hence the involvement of oxidation accompanying the decomposition process is ruled out. However, the subsequent exothermic steps in DTA suggest that decomposition is accompanied by oxidation which may involve atmospheric oxygen.

Following is the stoichiometry of the different intermediates involved in the decomposition process of lanthanum tartrate.
I. $\quad \mathrm{La}_{2}\left(\mathrm{C}_{4} \mathrm{H}_{4} \mathrm{O}_{6}\right)_{3} \cdot 7 \mathrm{H}_{2} \mathrm{O}$

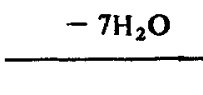
$\mathrm{La}_{2}\left(\mathrm{C}_{4} \mathrm{H}_{4} \mathrm{O}_{6}\right)_{3}$
[lanthanum tartrate
[lanthanum tartrate
crystals] anhydrous]
II. $\mathrm{La}_{2}\left(\mathrm{C}_{4} \mathrm{H}_{4} \mathrm{O}_{6}\right)_{3}$
[lanthanum tartrate anhydrous]
III. $\mathrm{La}_{2}\left(\mathrm{C}_{2} \mathrm{O}_{4}\right)_{3}$
[lanthanum oxalate]

$$
\stackrel{-\left(6 \mathrm{H}_{2} \mathrm{O}+6 \mathrm{C}\right)}{\longrightarrow} \quad \mathrm{La}_{2}\left(\mathrm{C}_{2} \mathrm{O}_{4}\right)_{3}
$$
[lanthanum oxalate]
IV. $\mathrm{La}_{2}\left(\mathrm{CO}_{3}\right)_{3}$
[lanthanum carbonate]

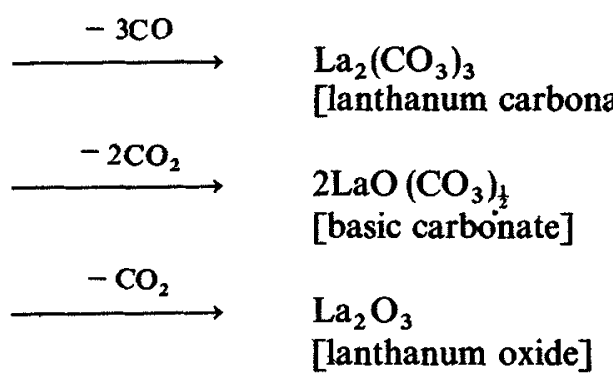
V. $2 \mathrm{LaO}\left(\mathrm{CO}_{3}\right)_{\frac{1}{2}}$
[basic carbonate]
[lanthanum oxide]

The decomposition pattern is typical of a hydrated metal tartrate (Alfred et al 1970). As such thermal decomposition study leaves no doubt about the stoichiometry of the material.

To study the reaction kinetics of solid state reactions involved, three equations were used for calculating the activation energy, the order of reaction and the frequency factor for the first stage of decomposition only, as in subsequent stages the sample characteristics cannot be controlled. The equations of Horowitz-Metzger (1963), Piloyan-Novikova (1966) and Coats-Redfern (1964) were used for this purpose.

Application of H-M equation leads to a good linear fit in the case of $f(\alpha)=(1-\alpha)^{\frac{1}{2}}$ 
Table 4. Energy of activation, order of reaction and frequency factor calculated from first stage of decomposition.

\begin{tabular}{lccc}
\hline $\begin{array}{l}\text { Relation } \\
\text { used }\end{array}$ & $\begin{array}{c}\text { Order of } \\
\text { reaction } \\
(n)\end{array}$ & $\begin{array}{c}\text { Frequency } \\
\text { factor } \\
(Z)\end{array}$ & $\begin{array}{c}\text { Energy of } \\
\text { activation }\left(E_{a}\right) \\
(\text { Kcal } / \mathrm{mol})\end{array}$ \\
\hline Horowitz-Metzger & $\frac{1}{2}$ & - & 9.426 \\
Piloyan-Novikova & - & $5.49 \times 10^{6}$ & 6.669 \\
Coats-Redfern & - & $3.653 \times 10^{4}$ & 7.254 \\
\hline
\end{tabular}

which indicates a contracting cylindrical mechanism of decomposition. The CoatsRedfern method also gives a linear fit for $g(\alpha)=2\left[1-(1-\alpha)^{\frac{1}{2}}\right]$, thereby suggesting the same mechanism of decomposition. Table 6 gives the activation energy, order of reaction and frequency factor as calculated from the first stage of decomposition. As is evident from table 4, the values of kinetic parameters like activation energy and frequency factor obtained by the application of three kinetic equations (viz. $\mathrm{H}-\mathrm{M}$, $\mathrm{P}-\mathrm{N}$ and $\mathrm{C}-\mathrm{R}$ for $E_{a}$ and $\mathrm{P}-\mathrm{N}$ and $\mathrm{C}-\mathrm{R}$ for frequency factor as well) are in reasonably good agreement. An agreement on the reaction mechanism leading to decomposition as suggested by the application of Coats-Redfern and HorowitzMetzger relation is noteworthy: both indicating contracting cylinder-kinetic model as the appropriate one to explain the results obtained in the present case.

\subsection{Magnetic characteristics}

Magnetic characteristic of the material grown was studied using Gouy's balance at room temperature $\left(34^{\circ} \mathrm{C}\right)$. The magnetic susceptibility measurements indicated the material to be diamagnetic.

\section{Conclusion}

(i) The gel-grown system involving the use of lanthanum nitrate or lanthanum chloride as the upper reactant and sodium metasilicate gel impregnated with tartaric acid leads to crystallization of lanthanum tartrate.

(ii) Chemical analysis supplemented by the results of infra-red spectroscopy and TGA establish the crystals to be hydrated; the chemical composition being $\mathrm{La}_{2}\left(\mathrm{C}_{4} \mathrm{H}_{4} \mathrm{O}_{6}\right)_{3} \cdot 7 \mathrm{H}_{2} \mathrm{O}$.

(iii) The x-ray and electron diffraction results reveal crystallinity of the gel-grown lanthanum tartrate crystals.

(iv) The results of thermal analysis (DTA, TGA and DTG) suggest the material to be thermally unstable beyond $60^{\circ} \mathrm{C}$. The decomposition of the material at $70 \mathrm{eV}$ of energy is suggested by the fragmentography in the mass spectrum. Changes in the electron diffraction pattern recorded immediately or after some time of loading also reveal changes in the crystalline character of the material due to electron beam heating and the presence of waters of hydration (Lorento 1975); the diffraction patterns revealing transition.from poly-crystalline to nearly amorphous pattern.

(v) Application of Horowitz-Metzger and Coats-Redfern relations in understanding the reaction kinetics of solid state reactions leading to decomposition of the 
crystalline material suggests the contracting cylinder-kinetic model to explain the decomposition.

(vi) Magnetic susceptibility measurements indicate the material to be diamagnetic.

\section{Acknowledgements}

The authors (NKG and KKR) are thankful to UGC and to the university authorities for research fellowships. The research work has been partially supported by the UGC. We are thankful to Prof. Y Prakash for his interest.

\section{References}

Alferd C, Latz G, Litant I and Rubin B 1970 Analytical calorimetry (New York \& London: Plenum) 255 Coats A W and Redfern J P 1964 Nature (London) 20168

Eyring L 1964 Progress in science and technology of rare earths (New York: Pergamon Press) $1 \& 2416$

Horowitz H H and Metzger G 1963 Anal. Chem. 351464

Kotru P N and Gupta N K 1983 Bull. Elect. Microsc. Soc. India 7119

Kotru P N, Gupta N K and Raina K K 1985 J. Mater. Sci. 2190

Lorento M H 1975 Physicochemical methods of mineral analysis (ed) A W Nicol (New York: Plenum Press)

Niekerk J V and Schoening F R L 1951 Acta. Crystallogr. 435381

Piloyan G O and Novikova O S 1966 Russ. J. Inorg. Chem. 12313 